\section{Phytophotodermatitis verhindern}

etzt wird sie wieder aktuell: die Phytophotodermatitis, hervorgerufen durch den Hautkontakt mit Psoralen- oder Furocumarin-haltigen Pflanzen wie Pastinak oder Riesenbärenklau (Foto). Die Haut reagiert nach kombiniertem Kontakt mit

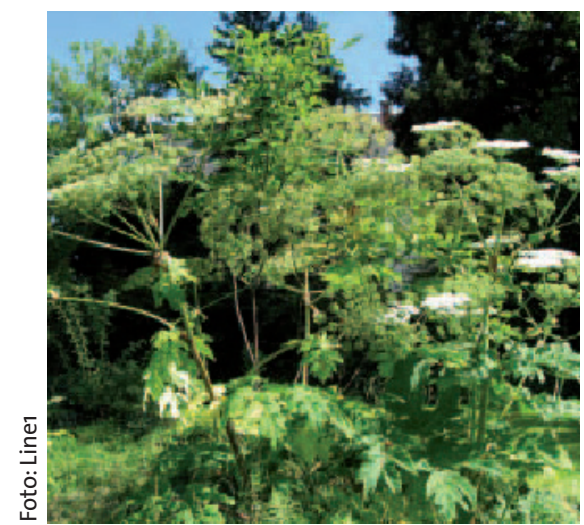

Pflanze und Licht mit erythematösen, vesikulären oder bullösen Läsionen. Verwechselungen mit Herpes simplex oder einer körperlichen Misshandlung sind vorgekommen. Die Aufklärung des Patienten oder der besorgten Eltern über die Ursache der Läsionen ist wichtig. In schweren Fällen müssen systemische Glukokortikoide gegeben werden, ansonsten wird topisch behandelt. Eine Prophylaxe ist möglich: In einem Zeitfenster von 30 Minuten bis zwei Stunden nach Exposition kann der Pflanzensaft abgewaschen werden, ohne dass größere Mengen in die Haut diffundieren. Eine anschließende zwei- bis dreitägige Sonnenkarenz kann die Dermatitis fast sicher verhindern. $b k$

Carlsen K et al. J Am Acad Dermatol 2007; 57 : S88-91

\title{
Lungenalter als Anti-Rauch-Argument
}

U

ntersuchungsergebnisse in Form von Messwerten sagen den Patienten oft wenig und führen nicht zu einer Änderung von Lebensgewohnheiten. Das zeigt sich auch, wenn man Patienten motivieren möchte, mit dem Rauchen aufzuhören. Effektiver als das Mitteilen des FEV ${ }_{1}$ aus der Spirometrie ist die Angabe des daraus abzuleitenden „Lungenalters“ (Alter eines gesunden Menschen mit der gleichen
Lungenfunktion). In einer Studie konnte man damit doppelt so viele Probanden zum Tabakverzicht bewegen wie mit der Kommunikation der reinen Werte, nämlich $13,6 \%$ vs. $6,4 \%$. Alle 561 Teilnehmer hatten gleichermaßen eine Beratung und das Angebot für eine intensive Unterstützung bei der Entwöhnung erhalten. red

Parkes G et al. BMJ 2008; 336: 598-600

\section{Vorsicht: Bodybuilder-Akne}

D er Anabolikamissbrauch bei Freizeitsportlern hat zugenommen. Die gesundheitlichen Risiken werden dabei gerne ausgeblendet - offensichtlich auch von Ärzten und Apothekern, die etwa $50 \%$ der verwendeten Substanzen wie Sustanon oder Nandrolondecanoat verfügbar machen. Eine der häufigsten Nebenwirkungen ist die Bodybuilder-Akne, die leicht bis schwer oder sogar fulminant verlaufen kann. Begleitende Beschwerden wie psychische Veränderungen, Gynäkomastie, Ödemneigung, erhöhter BMI und verminder- tes Hodenvolumen untermauern den Verdacht auf Doping-Akne. Behandelt wird wie auch sonst bei Akne üblich, die Anabolika werden natürlich abgesetzt. Eine Aufklärung des Patienten über die gesundheitlichen Risiken der Anabolika, vor allem die kardiovaskuläre Toxizität und die Entwicklung einer Anabolikaabhängigkeit, ist ebenfalls indiziert.

$b k$

Melnik B et al. J Dtsch Dermatol Ges 2007; 5: 110-7

\section{Anaphylaxie durch Echinokokkose}

D ie zystische Echinokokkose wird vor allem durch Finnen des Hundebandwurms (Echinococcus granulosus) hervorgerufen. Die Bandwurmeier werden über die Nahrung aufgenommen und entwickeln sich meist in der Leber zur Jugendform des Bandwurms. Die meist symptomlosen Zysten (Foto) enthalten neben den Bandwurmköpfen eine stark antigenhaltige Flüssigkeit, weshalb es bei Ruptur, in seltenen Fällen auch ohne erkennbares Trauma, zu anaphylaktischen Reaktionen kommen kann. Bei Patienten, die aus Endemiegebieten wie Naher Osten oder Mittelmeergebiet stammen oder dort Urlaub gemacht haben, sollte bei unklar ausgelöster Anaphylaxie an diese parasitäre Erkrankung gedacht werden. So waren bei einer 48jährigen Türkin erst nach drei Anaphylaxieepisoden Hydatidenzysten in der Leber entdeckt und entfernt worden. Eine sechsmonatige Albendazol-Behandlung wurde verordnet, eine Kontrolluntersuchung fand jedoch nicht statt. Da-

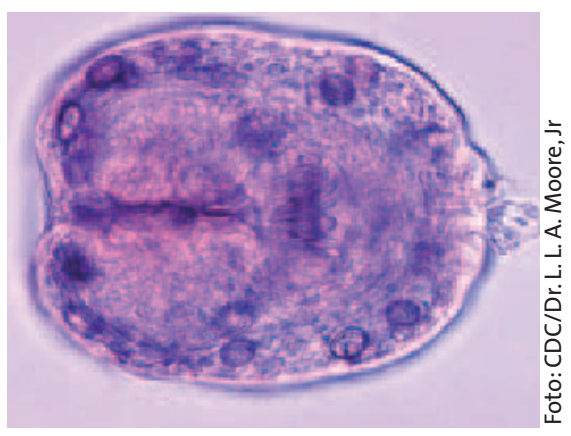

nach hatte die Frau fünf Jahre lang Flusherscheinungen im Gesicht. Erst nach erneuter Anaphylaxie wurden wieder Hydatidenzysten in der Leber gefunden, das Serum-Gesamt-IgE lag bei fast 17.000 kU/l. Nach erneuter Operation und Albendazolgabe sank das $\operatorname{IgE}$ auf $4.350 \mathrm{kU} / \mathrm{l}$. Es wird empfohlen, behandelte Echinokokkose-Patienten über zwei Jahre nachzubeobachten. Wenn erhöhte IgE-Spiegel persistieren, bleibt auch die Anaphylaxiegefahr erhöht.

Gelincik A et al. Int Arch Allergy Immunol 2007; 143: 296-8 